\title{
Qualitative and Quantitative Characterisation of Minor Chemical Elements in Diesel Particulate Matter by Laser Induced Breakdown Spectroscopy ${ }^{\dagger}$
}

\author{
Richard Viskup *, Christoph Wolf and Werner Baumgartner \\ Institute of Biomedical Mechatronics, Johannes Kepler University Linz, Altenberger strasse 69, 4040 Linz, \\ Austria; Christoph.Wolf@jku.at (C.W.); Werner.Baumgartner@jku.at (W.B.) \\ * Correspondence: Viskup@gmail.com or Richard.Viskup@jku.at; Tel.: +43-732-2468-4811 \\ + Presented at 1st International Electronic Conference on Applied Sciences, 10-30 November 2020; Available \\ online: https://asec2020.sciforum.net/.
}

Published: 10 November 2020

\begin{abstract}
In this research we investigate the minor chemical elements contained in the Diesel particulate matter (DPM) exhaust emissions, generated by in - use Diesel engine passenger vehicles. For this purpose we apply a high resolution optical emission spectroscopy technique, for precise spectrochemical analysis of Diesel particulate matter. By means of the Laser Induced Breakdown Spectroscopy (LIBS) analytical method we quantify detected minor chemical elements in DPM. Particulate matter samples were obtained from in-use Diesel engine passenger vehicles of diverse types and models from major brand car producers in Europe. We analysed particulate matter, extracted from the exhaust manifold part, from vehicles, that are used in daily life environment. The LIBS results have revealed the presence of minor chemical elements in DPM-Silicon, Nickel, Titan, Potassium, Strontium and Molybdenum with diverse concentration.
\end{abstract}

Keywords: Particulate Matter; Diesel Particulate Matter; particulates; soot; carbon emissions; pollutant emissions; vehicle emissions; exhaust emissions; ultrafine particles; metallic nanoparticles; trace metals; trace elements; trace emission; air quality; laser induced breakdown spectroscopy; laser induced plasma spectroscopy; LIBS; LIPS

\section{Introduction}

Diesel engine emissions and Diesel vehicles emission monitoring [1,2] are important topics nowadays. This is because its real state reflects on current quality of air flow in the cities, city-suburbs, industrial or rural areas. Thus influence the number of inhalant nanoparticles within the particulate matter in air, and form the current air pollution of our "modern" civilisation. To breathe the nonpolluted clean air is very important for our human health-not only for lungs and cardiovascular system, but also for the brain and central nervous system [3,4]. Nowadays, PM and metallic nanoparticles are the key sources of many diseases and illnesses or deaths. Therefore, it should be among our highest priorities to rigorously explore and understand the chemical composition of particulate matter. The knowledge of this information can help to find new techniques to precisely measure and quantify the content of different chemical elements adsorbed inside the small PM and hence minimise the vehicle's emissions.

In this study we used high resolution Laser Induced Breakdown Spectroscopy technique [5] for qualitative and quantitative spectrochemical analysis of Diesel Particulate Matter (DPM) collected from in-use Diesel engine passenger vehicles. We analysed particulate matter from different vehicles of major EU car producers, used in daily life environment. 


\section{Methodology}

\subsection{LIBS Setup}

Laser induced breakdown spectroscopy (LIBS) is a contact-less optical measurement technique for qualitative and quantitative elemental composition analysis of various forms of materials $[6,7]$. The results from the analytical measurements are the recorded spectra of atomic, ionic and molecular spectral lines. From LIBS spectra, the elemental chemical composition of the examined sample can be obtained. The qualitative spectral information can be further calibrated, to obtain quantitative results. The LIBS technique provides very sensitive and rapid analytical measurements, without sample pretreatment, in the range of ppm levels. Experimental setup for LIBS measurement, consists of high intensity pulsed laser system, experimental chamber, collection optics and high precision optical spectrometer. Laser beam is guided via optical mirrors into the focusing lens. Plasma is generated by focusing of high power laser radiation into the material.

As the laser source for plasma generation we have used solid state Nd:YAG laser from Quantel, with pulse duration $8.5 \mathrm{~ns}$, wavelength $1064 \mathrm{~nm}$ and laser pulse energy $300 \mathrm{~mJ}$. Optical emission from plasma were detected with high resolution Echelle spectrograph, Aryelle Butterfly, LTB Berlin and ICCD detector. Spectrometer provide measurements with spectral resolution from $3 \mathrm{pm}-7 \mathrm{pm}(\mathrm{pm}=$ picometre) for VUV and $4 \mathrm{pm}-8 \mathrm{pm}$ for VIS range. The delay time was set to $1 \mu \mathrm{s}$ and gate width to $2 \mu \mathrm{s}$.

\subsection{Diesel Particulate Matter Collection and Sample Preparation}

More than seventy different samples collected from in-use Diesel engine passenger vehicles of major brand car producers in Europe have been analysed by LIBS. Vehicles selected for the DPM sample collection were from our daily life environment. Diesel Particulate Matter was collected and extracted directly from the tail pipe at the end of the exhaust system. The collected particulate matter from vehicles tail pipe deposits has been mechanically pressed into small pellets with $6 \mathrm{~mm}$ diameter and with a flat, disc-like shape.

\section{Results and Discussion}

\subsection{Qualitative Characterisation of DPM}

In Laser Induced Breakdown Spectroscopy signal recorded from different Diesel Particulate Matter samples are dominating spectral lines from Carbon, Iron, Magnesium, Aluminium, Chromium, Zinc, Sodium and Calcium. These lines were identified as major chemical elements of Diesel Particulate Matter, further details related to this topic are discussed in the reference $[8,9]$.

High resolution optical emission spectra were also used to identify the minor chemical elements of DPM. For this case we focus our attention to minor chemical elements, particularly to dominant spectral lines from atomic and ionic emission from: Silicon, Nickel, Titan, Potassium, Strontium and Molybdenum.

In Table 1 are summarised measured analytes, the spectral atomic or ionic lines used for analytical LIBS measurements and number of samples where the minor element has been successfully detected. The spectral lines data included in the Table 1 are obtained from the National Institute of Standards and Technology (NIST) atomic spectra database.

Table 1. Spectral lines used for analytical LIBS measurements and number of DPM samples with detected minor chemical element.

\begin{tabular}{rccc}
\hline Analyte & $\begin{array}{c}\text { Spectral } \\
\text { line }\end{array}$ & $\begin{array}{c}\text { Wavelength } \\
\text { (nm) }\end{array}$ & $\begin{array}{c}\text { Detected } \\
\text { in/Total Number } \\
\text { of Samples }\end{array}$ \\
\hline $\mathrm{Si}$ & $\mathrm{Si}$ & 288.16 & $63 / 67$ \\
$\mathrm{Ni}$ & $\mathrm{Ni} \mathrm{II}$ & 221.64 & $43 / 67$ \\
$\mathrm{Ti}$ & $\mathrm{Ti} \mathrm{II}$ & 334.94 & $32 / 67$
\end{tabular}




\begin{tabular}{cccc} 
K & K I & 766.48 & $50 / 67$ \\
Sr & Sr II & 407.77 & $35 / 67$ \\
Mo & Mo I & 390.29 & $55 / 67$ \\
\hline
\end{tabular}

\subsection{Calibration Procedure}

For the quantification of the LIBS signal, internal laboratory calibration standards with different concentrations of selected major and minor chemical elements in the particulate matter were prepared. Based on our previous qualitative and quantitative analytical LIBS measurements of different types of DPM matrices performed by high resolution LIBS technique, similar particulate matter matrices were produced as internal standards in our laboratory.

Calculated calibration curves with regression parameter R2, 95\% confidence limits and prediction bands for: Silicon, Nickel, Titan, Potassium, Strontium and Molybdenum are shown in Figure 1. For the calibration purposes we used either the linear fitting or the nonlinear allometric fitting procedures, depending on measured and calculated data from the LIBS analyses. The concentrations and calibration curves of individual chemical elements are shown in weight percent (wt \%) units.

\subsection{Quantitative Characterisation of DPM}

By using calibration function for each minor element and signal from DPM samples it was possible to extract the quantitative information about the concentration of chemical elements by LIBS. In Table 2 are summarised the results from quantitative determination of minor chemical elements in DPM collected from different in-use Diesel engine passenger vehicles. In particular, obtained maximum, minimum, mean value and median concentrations of minor elements in (wt \%). For statistic reasons summary Table 2, only include these DPM samples, where the minor chemical element concentration was within the accepted calibration interval.

Table 2. Summary of quantitative determination of minor chemical elements in DPM obtained by high resolution LIBS technique. Calculated maximum, minimum, mean value and median concentrations of minor elements in different DPM from in-use Diesel engine passenger vehicles. Values are in (wt \%).

\begin{tabular}{cccccc}
\hline Analyte & $\begin{array}{c}\text { Max. } \\
\text { Concent } \\
\text { ration } \\
\mathbf{( w t} \text { \%) }\end{array}$ & $\begin{array}{c}\text { Min. } \\
\text { Concent } \\
\text { ration } \\
\mathbf{( w t} \text { \%) }\end{array}$ & $\begin{array}{c}\text { Mean } \\
\text { Value } \\
\mathbf{( w t} \%)\end{array}$ & $\begin{array}{c}\text { Median } \\
\text { Value } \\
\mathbf{( w t ~ \% ) ~}\end{array}$ & $\begin{array}{c}\text { Number of DPM } \\
\text { Samples Used } \\
\text { for Statistics }\end{array}$ \\
\hline $\mathrm{Si}$ & 2.33 & 0.22 & 0.94 & 0.81 & 37 \\
$\mathrm{Ni}$ & 6.36 & 0.57 & 2.22 & 1.76 & 37 \\
$\mathrm{Ti}$ & 3.95 & 0.36 & 1.21 & 0.95 & 29 \\
$\mathrm{~K}$ & 2.23 & 0.1 & 0.48 & 0.37 & 50 \\
$\mathrm{Sr}$ & 0.99 & 0.01 & 0.09 & 0.04 & 35 \\
$\mathrm{Mo}$ & 5.9 & 0.16 & 1.32 & 0.72 & 52 \\
\hline
\end{tabular}



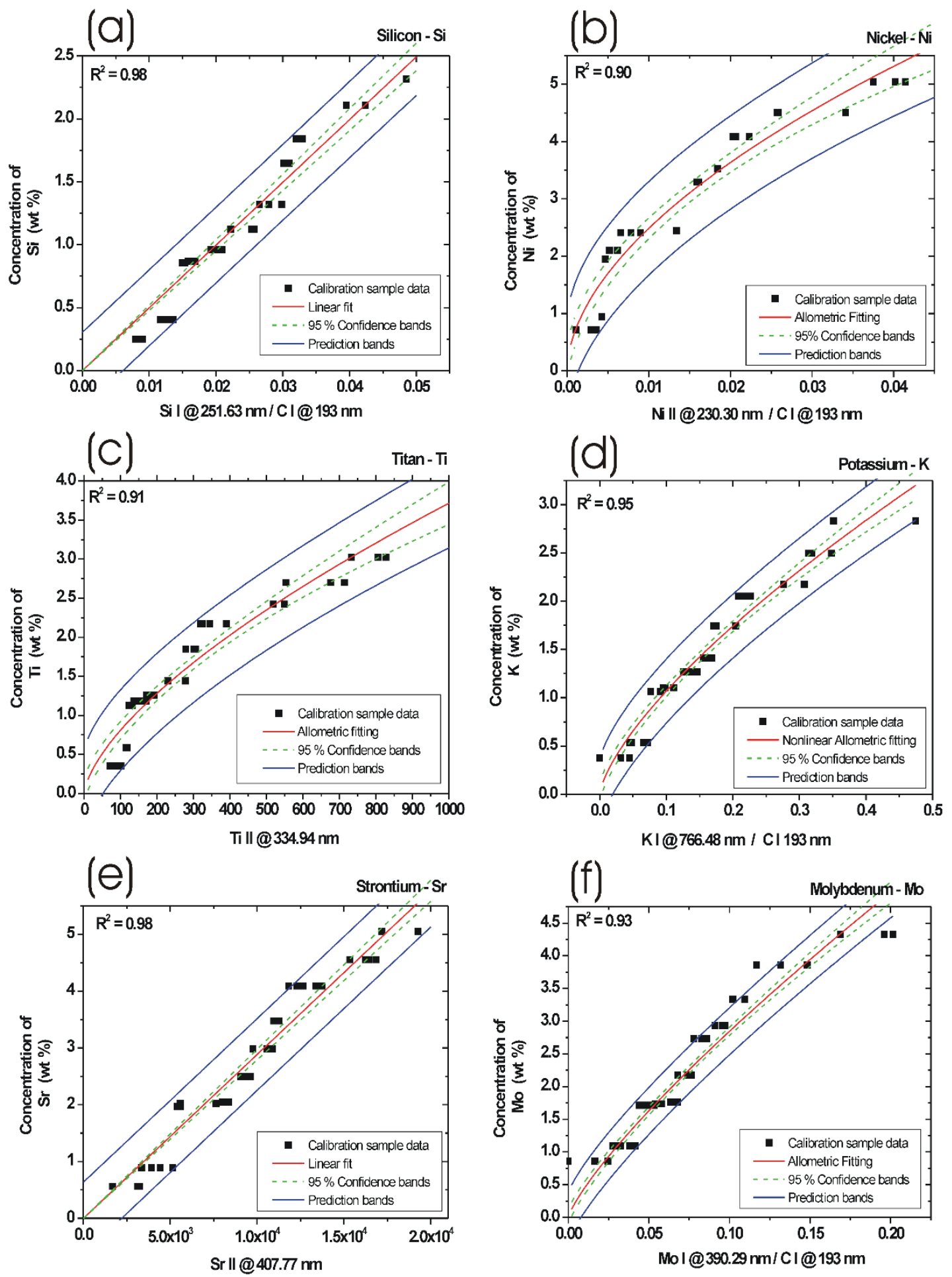

Figure 1. Calibration curves (red line) including regression parameter $\mathrm{R}^{2}, 95 \%$ confidence limits (green dashed line) and prediction bands (blue line) for: (a) Silicon, (b) Nickel, (c) Titan, (d) Potassium, (e) Strontium, (f) Molybdenum obtained from laboratory prepared PM calibration standards. Concentrations of elements are in weight percent (wt \%).

\section{Conclusions}

In this proceeding, we have shown the qualitative results and quantitative procedure for characterisation of the minor chemical elements in the Diesel particulate matter collected from in-use Diesel engine passenger vehicles. Particulate matter samples have been analysed spectrochemicaly by means of a high resolution laser induced breakdown spectroscopy. The LIBS analytical results 
have shown the presence of minor chemical elements: $\mathrm{Si}, \mathrm{Ni}, \mathrm{Ti}, \mathrm{K}, \mathrm{Sr}, \mathrm{Mo}$. Special emphases were given to the quantification of the LIBS spectral signal and to the calibration curves from selected minor chemical elements of DPM. Measured minor elements $\mathrm{Si}, \mathrm{Ni}, \mathrm{Ti}, \mathrm{K}, \mathrm{Sr}$, Mo together with major elements $\mathrm{C}, \mathrm{Fe}, \mathrm{Mg}, \mathrm{Al}, \mathrm{Cr}, \mathrm{Zn}, \mathrm{Na}$ and $\mathrm{Ca}$ are forming important part of the Diesel particulate matter composition. All these chemical elements are contributing to overall DPM exhaust emissions from Diesel engine passenger vehicles.

Author Contributions: All authors contributed to the manuscript. For further details please contact the corresponding author.

Funding: Authors would like to thank for the financial support of the Linz Center of Mechatronics (LCM), project number K 24400/LCM. This research was funded by Austrian Science Fund (Fonds zur Förderung der wissenschaftlichen Forschung) FWF, project number P 27967. Austrian Science Fund: P 27967

Acknowledgments: Authors would like to thank Dr. Maria Rusnak for the proofreading and for the valuable corrections. Open Access Funding by Austrian Science Fund (Fonds zur Förderung der wissenschaftlichen Forschung) FWF (P 27967). Authors would like to acknowledge the financial support of the Linz Center of Mechatronics (LCM), project number K 24400/LCM.

Conflicts of Interest: The authors declare no conflict of interest.

\section{References}

1. Ntziachristos, L.; Papadimitriou, G.; Ligterink, N.; Hausberger, S. Implications of Diesel emissions control failures to emission factors and road transport NOx evolution. Atmos. Environ. 2016, 141, 542-551, doi:10.1016/j.atmosenv.2016.07.036.

2. Zacharof, N.; Tietge, U.; Franco, V.; Mock, P. Type approval and real-world $\mathrm{CO}_{2}$ and $\mathrm{NOx}$ emissions from EU light commercial vehicles. Energy Policy 2016, 97, 540-548, doi:10.1016/j.enpol.2016.08.002.

3. Calderón-Garcidueñas, L.; Mora-Tiscareño, A.; Ontiveros, E.; Gómez-Garza, G.; Barragán-Mejía, G.; Broadway, J.; Chapman, S.; Valencia-Salazar, G.; Jewells, V.; Maronpot, R.R.; et al. Air pollution, cognitive deficits and brain abnormalities: A pilot study with children and dogs. Brain Cogn. 2008, 68, 117-127, doi:10.1016/j.bandc.2008.04.008.

4. Block, M.L.; Calderon-Garciduenas, L. Air pollution: Mechanisms of neuroinflammation and CNS disease Trends Neurosci. 2009, 32, 506-516, doi:10.1016/j.tins.2009.05.009.

5. Noll, R. Laser-Induced Breakdown Spectroscopy, Fundamentals and Applications; Springer: Berlin, Germany, 2012.

6. Miziolek, A.W.; Palleschi, V.; Schechter, I. Laser-Induced Breakdown Spectroscopy (LIBS): Fundamentals and Application; Cambridge University Press: New York, NY, USA, 2006.

7. Cremers, D.A.; Radziemski, L.J. Handbook of Laser-Induced Breakdown Spectroscopy; John Wiley \& Sons Inc.: New Delhi, India, 2013.

8. Viskup, R.; Wolf, C.; Baumgartner, W. Qualitative and quantitative characterisation of major elements in particulate matter from in-use diesel engine passenger vehicles by LIBS. Energies 2020, 13, 368, doi:10.3390/en13020368

9. Viskup, R.; Wolf, C.; Baumgartner, W. Major Chemical Elements in Soot and Particulate Matter Exhaust Emissions Generated from In-Use Diesel Engine Passenger Vehicles. In Introduction to Diesel Emissions; Viskup, R., Ed.; IntechOpen London, SW7 2QJ, UK: 2020; doi:10.5772/intechopen.90452.

Publisher's Note: MDPI stays neutral with regard to jurisdictional claims in published maps and institutional affiliations.

C 2020 by the authors. Submitted for possible open access publication under the terms and conditions of the Creative Commons Attribution (CC BY) license (http://creativecommons.org/licenses/by/4.0/). 